\title{
Photoinduced Absorption Spectroscopy as a Tool in the Study of Electron Injection and Recombination in CdS quantum Dots Sensitized ZnO Solar Cell
}

\author{
Idriss Bedja \\ Department of Optometry, College of Applied Medical Sciences, \\ King Saud University, Saudi Arabia; \\ Email: bedja@ksu.edu.sa
}

Thin films of $\mathrm{ZnO}$ nanoparticulate films have been prepared and modified with CdS quantum dots via chemical bath deposition technique. Photoinduced absorption spectroscopy (PIA), where the excitation is provided by a square-wave modulated (on/off) monochromatic diode light source, is a multipurpose tool in the study of dye-sensitized solar cells. Here, we use PIA as a tool for the study of a quantum-dot modified metal oxide nanostructrued electrode. Oxidized quantum dots can easily be obtained from the spectra of transient species, and their kinetics can be explored using time-resolved techniques. $\mathrm{ZnO}$ based $\mathrm{CdS}$ photoelectrode has demonstrated best performances in both photoelectrical response and broadening response into visible with a maximum IPCE of $87 \%$ at $400 \mathrm{~nm}$. Time constant for electron injection or hole transfer was relatively fast $(44 \mu s)$ and proves at least a well pore filling of $\mathrm{ZnO}$ film by ultra fine $\mathrm{CdS}$ particles.

\section{Introduction:}

When used as electrodes in regenerative photoelectronchemical cells, wide band-gap nanostructured metal oxide (MO) semiconductor materials can serve as carriers of solar absorbers such as organometallic dyes [1-4] or inorganic narrow band-gap semiconductors (quantum dots: Q-dots) [5-8]. Power conversion efficiencies in the range of $8-12 \%$ in diffuse daylight have been obtained in the sensitization of highly porous $\mathrm{TiO}_{2}$ film with only a sub monolayer required ruthenium complex. [1] In the other hand, wide band gap semiconductors have been sensitized by short band gap (Q-dots) semiconductor materials $\mathrm{CdSe} / \mathrm{TiO}_{2}$ [4], $\mathrm{ZnO} / \mathrm{ZnS}[8]$ as alternative to dye sensitization. Under visible light irradiation, only the sensitizer is excited, and electrons transferred to their conduction band are injected to the inactivated MO semiconductor 
conduction band. If the valence band of the sensitizer is more cathodic than the valence band of MO, hole generated in the semiconductor remains there and can not migrate to MO. Thus, the two charges will be separated effectively.

In contrast with the dye sensitized solar cells, fundamental understanding for the factors controlling the interfacial electron transfer reactions in Q-dots modified metal oxide based solar cells is limited. Photoinduced absorption spectroscopy is a suitable method to obtain spectral and kinetic information of the Q-dot sensitized MO electrodes. In this work, we use photoinduced absorption spectroscopy (PIA) where on/off modulation of a light source is used. While PIA is a popular tool in the study of photoactive polymers $[9,10]$, organic solar cells $[11,12]$ and DSC (dye sensitized solar cells), there is, in our knowledge, no PIA published work on Q-dot sensitized MO solar cell. Here, we study photoelectrochemistry and PIA studies on CdS q-dots sensitized $\mathrm{ZnO}$ nanostructured electrodes.

\section{Experimental:}

\subsection{Preparation of $\mathrm{ZnO}$ Nanostructured Films:}

Colloidal $\mathrm{ZnO}$ was prepared as previously published [13]. $50 \mathrm{mmol}(11 \mathrm{~g})$ of zinc acetate dehydrate was stirred in $100 \mathrm{ml}$ absolute ethanol at room temperature and became an opaque suspension. $50 \mathrm{mmol}(21 \mathrm{ml})$ of tetramethylam-monium hydroxide (TMAOH) in methanol was added. Then the obtained suspension was heated and refluxed $(80 \mathrm{C})$ for about $30 \mathrm{~min}$. During reflux, the solution became slowly white due aggregation of the colloids. Then, the suspension was left to cool down and settle overnight. After what, it is decanted and washed with ethanol. Using a rotary evaporator, $\mathrm{ZnO}$ was concentrated until visibly viscous. Gel-films were then obtained by doctor blading the colloidal solution onto $\mathrm{SnO}_{2}$ doped-indium conducting glass (ITO) using adhesive tape (Scotch Magic) as spacer. The films were then fired in a hot-air stream at $350 \mathrm{C}$ for $30 \mathrm{~min}$ and the thicknesses were determined by profile-metry and were typically between $2-3 \mu \mathrm{m}$.

\subsection{Surface Modification of $\mathrm{ZnO}$ by Quantum Dots of CdS:}

$\mathrm{ZnO}$ metal oxide nanostructured electrodes were successively dipped into an aqueous solution of saturated $\mathrm{Cd}\left(\mathrm{ClO}_{4}\right)_{2}$ and $0.1 \mathrm{M} \mathrm{Na}_{2} \mathrm{~S}$ for 1 and 2 min, respecttively. After each $\mathrm{CdS}$ layer deposition, the electrodes were heated at $125^{\circ} \mathrm{C}$ for $5 \mathrm{~min}$. 


\subsection{Characterization Methods:}

UV-Vis spectra were recorded using a Hewlett-Packard 8453 diode array spectrometer. The photoelectrochemical measurements were carried out in a layer quartz cell similar to that in Fig. (1) [also in Ref.14]. Two electrodes were inserted consisting of a reference $(\mathrm{Ag} / \mathrm{AgCl})$ and counter $(\mathrm{Pt}$ wire) electrodes.

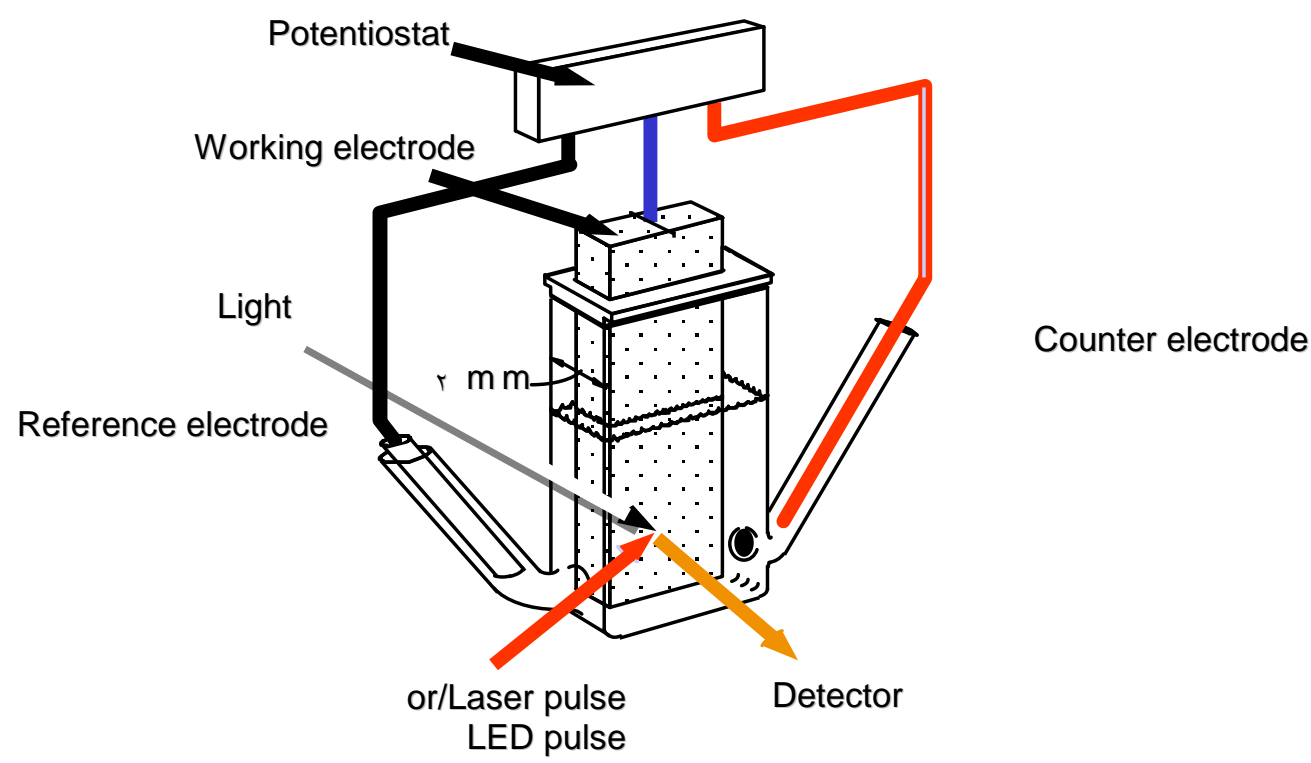

Fig. (1): Photoelectrochemical Cell (Quartz) [ Bedja, Ph.D. Dissertation 1996]

A Princeton Applied Research (PAR) Model 173 and 175 universal potentiostats were used in electrochemical measurements.

For PIA spectroscopy (Fig. 2), excitation of the sample was provided by light from a blue LED (Luxeon Star 1W, Royal Blue, $470 \mathrm{~nm}$ ), which was square-wave modulated (on/off) by electronical means using an HP 33120A waveform generator and a home- built LED driver system. The beam, with an intensity in the range of $0.5-30 \mathrm{~mW} / \mathrm{cm}^{2}$, excited a sample area of about $1 \mathrm{~cm}^{2}$. White probe light was provided by a $20 \mathrm{~W}$ tungsten-halogen lamp. A cutoff filter (Schott RG715) was used to minimize excitation of the sample by the probe light where indicated. The transmitted probe light was focused onto a monochromator (Acton Research Corporation SP-150) and detected using a UV- enhanced Si photo-diode, connected to a lock-in amplifier via a current amplifier (Stanford Research Systems models 830 and 570, respectively). For the time-resolved studies the output of the current amplifier was connected to a data acquisition board (National Instruments PCI-6052E). All PIA measurements were done at room temperature. 


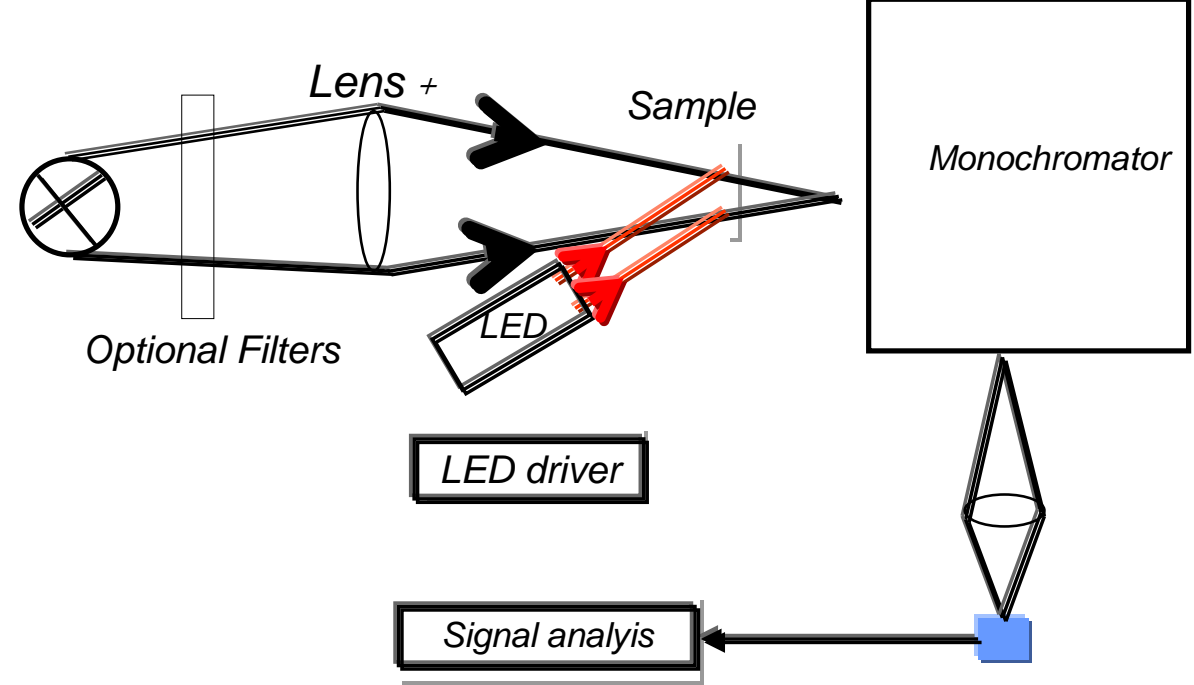

Fig. (2): Photoinduced Absorption Spectroscopy Set-up

\section{Results and Discussion:}

\subsection{XRD Pattern}

The X-ray diffraction (XRD) in figure 3 assess first the crystallinity of $\mathrm{ZnO}$ nanostruc-tured film (using Siemens D5000 apparatus) and shows clearly sharp and high-intensity peaks of CdS similar to those reported earlier by Y. Tak et al. [15].

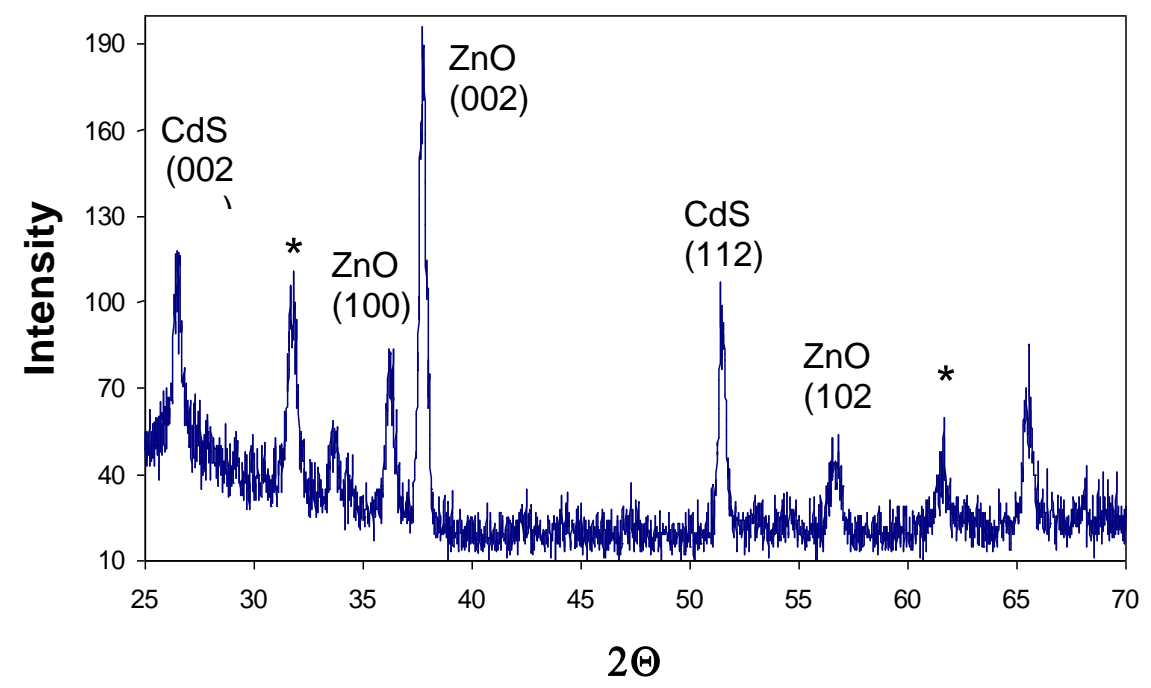

Fig. (3): XRD data of the as-prepared $\mathrm{CdS} / \mathrm{ZnO}$ film. (*: $\mathrm{SnO}_{2}$ substrate) 


\subsection{Absorption and IPCE Spectra:}

Absorption spectra have been recorded for both $\mathrm{ZnO}$ film before and after CdS modification (Inset of Fig. 4). CdS sensitized $\mathrm{ZnO}$ samples could absorb visible light and the absorption range increased up to $\sim 600 \mathrm{~nm}$.

The photoelectrochemical response of the $\mathrm{ZnO}$ electrode, before and after modification with $\mathrm{CdS}$, was evaluated by measuring the photocurrent of the electrode at va-rious excitation wavelengths. The incident photon-tophotocurrent efficiency (IPCE) was then determined from the expression (1) where $\mathrm{I}_{\mathrm{sc}}$ is the short-circuit current $\left(\mathrm{A} / \mathrm{cm}^{2}\right), \mathrm{I}_{\text {inc }}$ is the incident light intensity

$$
\operatorname{IPCE}(\%)=100 \times\left(1240 \times I_{\text {sc }}\right) /\left(\mathbf{I}_{\text {inc }} \lambda\right)
$$

$\left(\mathrm{W} / \mathrm{cm}^{2}\right)$, and $\lambda$ is the excitation wavelength (nanometers). The onset of photocurrent of $\mathrm{ZnO}$ based electrode is seen at a wavelength below $430 \mathrm{~nm}$. The photoresponse of $\mathrm{ZnO}$ electrode (Fig. 4A) has been extended to the visible range after $\mathrm{CdS}$ modification (Fig. $4 \mathrm{~b}$ ). High IPCE value have been mesasured (about $67 \%$ at $470 \mathrm{~nm}$ ).

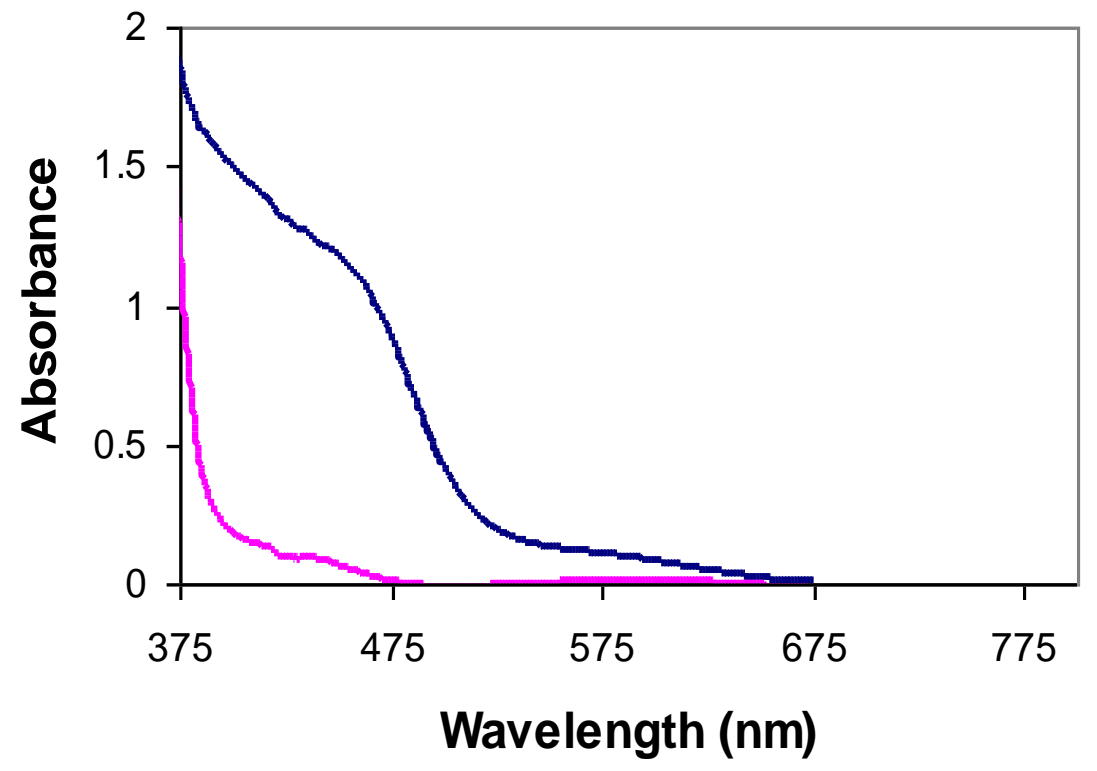

Fig. (4): Incident photon-to-current conversion efficiencies (IPCE) of $\mathrm{ZnO}$ Photoelectrode (A) before modification with $\mathrm{CdS}$ and (B) after modification with CdS. Inset: Absorption spectra of (a) $\mathrm{ZnO}$ particulate film and (b) $\mathrm{CdS}$ modified $\mathrm{ZnO}$ film. Electrolyte used was $\mathrm{Na} 2 \mathrm{~S} 0.1 \mathrm{M}, \mathrm{Na} 2 \mathrm{SO} 40.01 \mathrm{M}$. 
Fig. (5) shows the anodic and cathode current behavior under dark and illumination of $\mathrm{CdS}$ sensitized $\mathrm{ZnO}$ electrode sample. The generation of anodic current is well representative behavior of an n-type semiconductor.

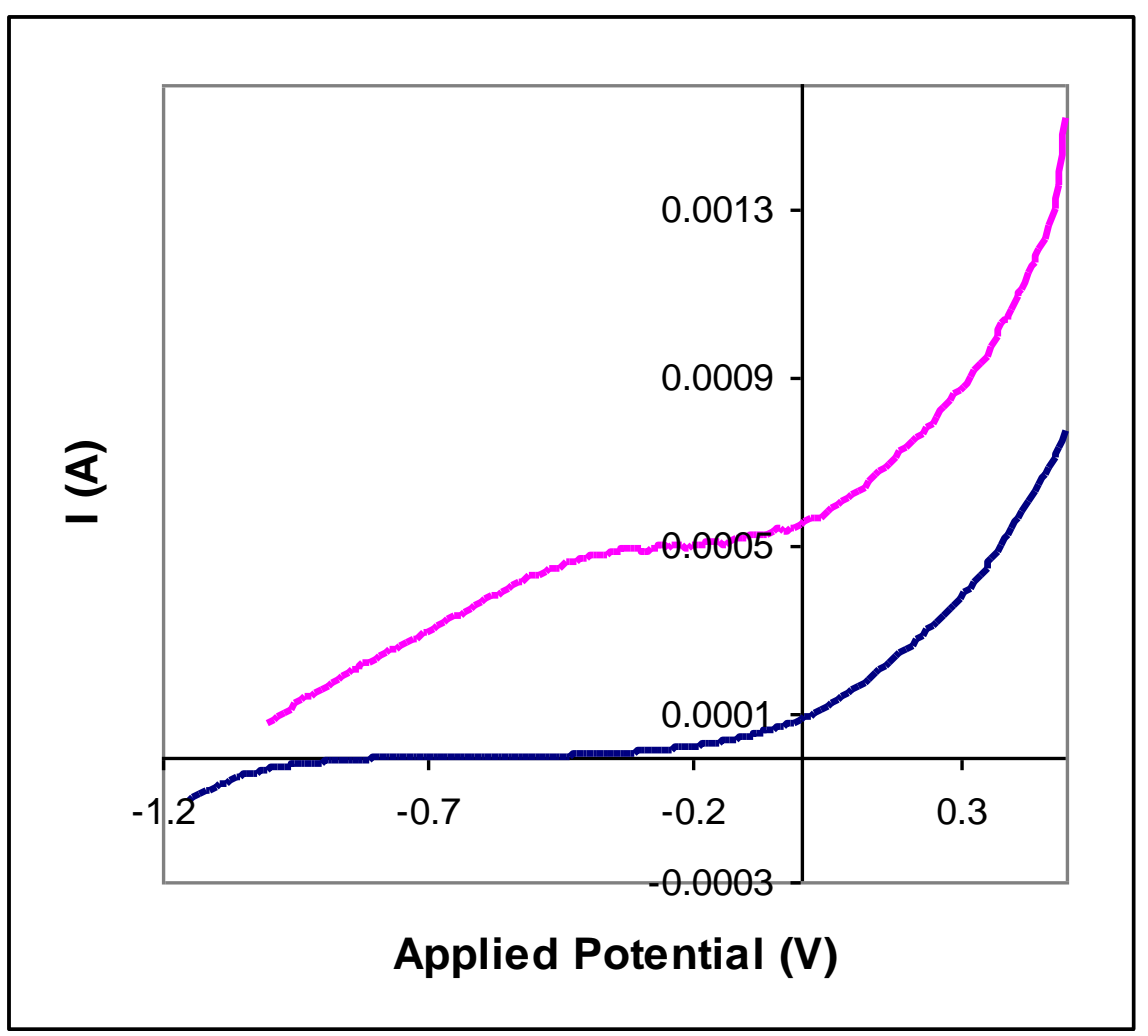

Fig. (5): Is the I-V characteristics of electrode: the traces were recorded in a dark and under $470 \mathrm{~nm}$ illumination. Electrolyte was $\mathrm{Na}_{2} \mathrm{~S} 0.1 \mathrm{M}, \mathrm{Na}_{2} \mathrm{SO} 40.01 \mathrm{M}$

\subsection{Photoinduced Absorption spectroscopy (PIA):}

\subsubsection{PIA spectrum}

Fig. (6): shows a typical PIA spectrum of $\mathrm{CdS}$ modified $\mathrm{ZnO}$ film without electrolyte for comparison (in air). The PIA spectrum clearly reflects the differential spectrum of $\mathrm{CdS}$ upon formation injection of electrons into $\mathrm{ZnO}$ conduc-tion band, with a bleach of the main absorption around $470 \mathrm{~nm}$. The remaining hole in $\mathrm{CdS}$ absorbs light and because valence band electrons are missing, an apparent increase in bandgap is seen (bleach, Moss-Burstein shift). 


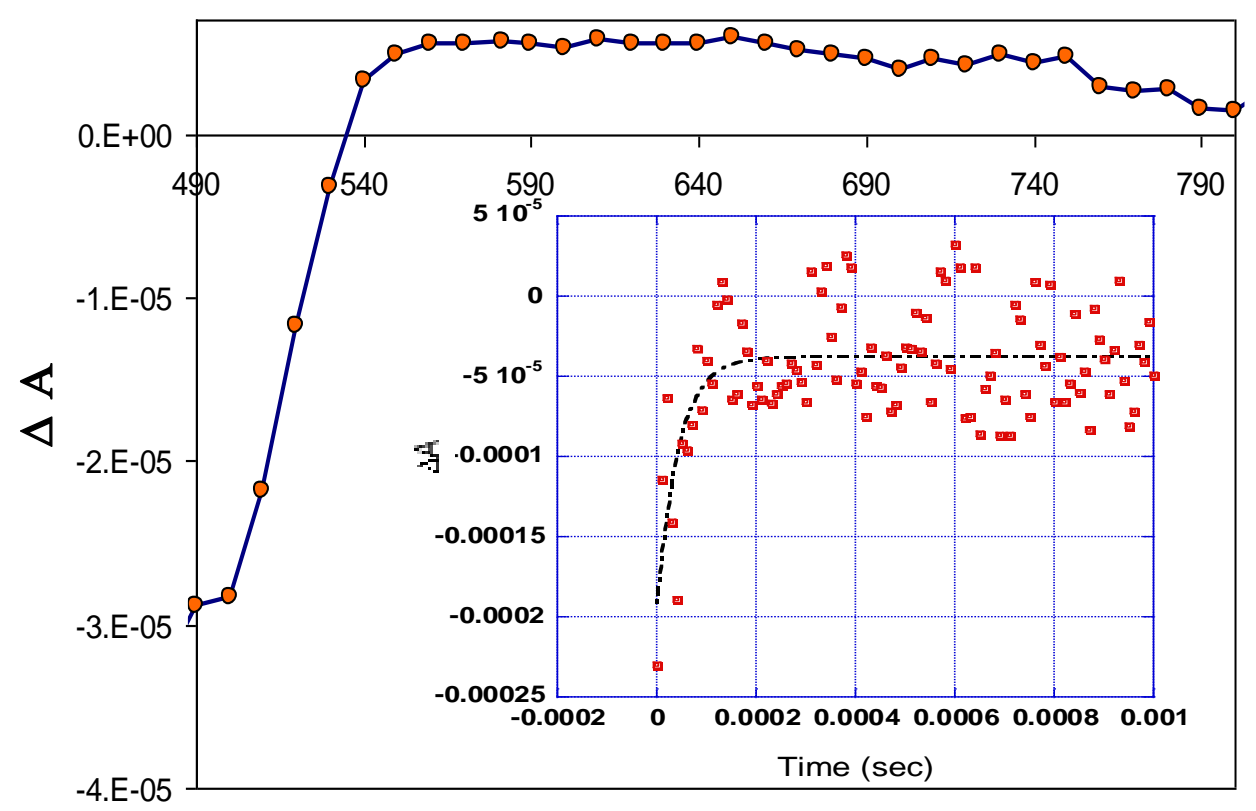

Fig. (6): Photoinduced absorption spectum of $\mathrm{CdS}$ modified $\mathrm{ZnO}$ electrode without electrolyte (in air). The spectrum was recorded using blue ligh (460 nm) excitation $\left(42 \mathrm{~mW} . \mathrm{cm}^{-2}\right)$ with a modulation frequency of $9 \mathrm{~Hz}$. Inset is a PIA transient absorption growth of a CdS modified $\mathrm{ZnO}$ electrode recorded at $500 \mathrm{~nm}$.

\subsubsection{PIA kinetics:}

Study of the kinetics in semiconductor sensitizing solar cells is not only feasible by laser flash photolysis but also possible using time-resolved PIA measurements. Inset of figure 6 shows such a PIA transient growth recorded at $500 \mathrm{~nm}$. Fitting the transient growth gives a (pseudo-) first-order rate constant for bleach (growth at $500 \mathrm{~nm}$ ) around $50 \mu \mathrm{s}$. This bleaching is due to hole-electron recombination which does not follow simple first-order kinetic but is characterized by a range of recombination times. This relatively fast growth proves at least a well pore filling of $\mathrm{ZnO}$ film by $\mathrm{CdS}$ particles. Contrarily to our relatively fast process that PIA has monitored, PIA can monitor even much slower processes like in the case of dye sensitized $\mathrm{TiO}_{2}[16]$ and $\mathrm{CdS}$ sensitized $\mathrm{TiO}_{2}$ in our different work submitted [17], recombination lifetimes are around $9 \mathrm{~ms}$ and $11 \mathrm{~ms}$, respecttively. We may conclude that in our system case $(\mathrm{CdS} / \mathrm{ZnO})$ the lower recombine-tion process delays up to less than a millisecond. In the case of a dye (D719) sensitized $\mathrm{TiO}_{2}$ compared to D719 sensitized $\mathrm{ZnO}$ electrodes [16], although $\mathrm{TiO}_{2}$ and $\mathrm{ZnO}$ have quite different electronic structure of their respective 
conduction band, it was observed identical recombination rates for both semiconductors. They concluded that the mole-cular state of the sensitized dye has a greater influence on the back-electron transfer on the kinetics than the conduction band electron state of the semiconductors. In our case, the same sensitizer on both $\mathrm{ZnO}$ (this work) and $\mathrm{TiO}_{2}$ (submitted work ref.17) is an inorganic semiconductor (CdS). This latter seems has lower influence on the backelectron transfer on the kinetics than the conduction band electron state of the semiconductors.

\section{Conclusion:}

Photoinduced absorption spectroscopy where the excitation is provided by an on/off monochromatic light source can give direct information on electron-injection and hole-electron recombination rates using spectra of transient species and their kinetics can be explored using time-resolved techniques. PIA can monitor slow processes and is much lower costly compared to laser flash photolysis. Unlike dye molecule sensiti-zers, the conduction band electron state of $\mathrm{ZnO}$ or $\mathrm{TiO}_{2}$ based photolectrode has greater influence on the back-electron transfer on the kinetics than the conduction band electron state of $\mathrm{CdS}$ semiconductor.

\section{Aknowledgements:}

The author would like to thank Dr Anders Hagfeldt for his authorization to use his lab. facilities at Uppsala University in Sweden, also Dr Gerrit Boschloo for his helpful discussions. The author would also thank King Abdullah Institute for Nano-technology at King Saud University, Riyadh, for the 2009 summer fellowship.

\section{References:}

1. B. O. Regan and M. Grätzel, Nature, 353, p737 (1991).

2. I. Bedja, S. Hotchandani and P. V. Kamat, J. Phys. chem. 98, p4133 (1994)

3. Bedja, S. Hotchandani and P. V. Kamat, J. Appl. Phys., 80, p8 (1996).

4. T. A. Heimer, E. J. Heilweil, C. A. Bignozzi and G. J. Meyer, J. Phys.Chem. A, 104, pp4256 (2000).

5. D. Liu and P. V. Kamat, J. Electrochem. Soc., 142, p835 (1995).

6. R. Vogel, P. Hoyer and H. Weller, J. Phys. Chem., 98, p3183 (1994).

7. J. Rabani, J. Phys. Chem., 93, p7707 (1989). 
8. I. Bedja, S. Hotchandani and P. V. Kamat, J. Berichte Der BunsenGesselschaft-Physical Chemistry Chemical Physics, 101, p1651 (1997).

9. G. Dellepiane, C. Cuniberti, D. Comoretto, G.F. Musso and G. Figari, Phys. Rev. B, 48, p7850 (1993).

10. Epshtein, G. Nakhmanovich, Y. Eichen and E. Ehrenfreund, Phys. Rev. B, 63, p125206 (2001).

11. L. Smilowitz, N.S. Sariciftci, R. Wu, C. Gettinger, A.J. Heeger and F. Wudl, Phys. Rev. B, 47, p13835 (1993).

12. W.J.E. Beek, M.M. Wienk, M. Kemerink, X.N. Yang and R.A.J. Janssen, J. Phys. Chem. B, 109, p9505 (2005).

13. M. Hilgendorff, L. Spanhel, C. Rothenhausler and G. Müller, J. Electrochem. Soc., 145, pp3632 (1998).

14. I. Bedja, "Photophysics and Photoelectrochemistry Studies on Nanocrystalline Semiconductor Systems. Mechanistic studies of Photosensitization and Modu-lation of Electron Transfer Kinetics". PhD. Thesis, 1996, Unversity of Quebec at Trois-Rivieres, Quebec, Canada

15. Y. Tak, H. Kim, D. Lee and K. Yong, Chem. Commun, 10, p1039 (2008).

16. C. Bauer, G. Boschloo, E. Mukhtar and A. Hagfeldt, J. Phys. Chem. B., 105, 4545 (2001).

17. I. Bedja, Materials Science-Poland, submitted, (2010). 